\title{
Melting of a new carbon -free waxed sponge iron in Electric Arc Furnace (EAF) for steelmaking
}

\author{
Jaleel Kareem Ahmad \\ College of Materials Engineering, Babylon University, Babylon, Iraq
}

\section{Email address:}

Jaleel_kareem@yahoo.com

\section{To cite this article:}

Jaleel Kareem Ahmad. Melting of a New Carbon -Free Waxed Sponge Iron in Electric Arc Furnace (EAF) for Steelmaking. International Journal of Materials Science and Applications. Special Issue: Steel and Direct Reduced Iron (sponge Iron) Industry.

Vol. 4, No. 2-1, 2015, pp. 1-6. doi: 10.11648/j.ijmsa.s.2015040201.11

\begin{abstract}
No problem with the melting of new carbon - free waxed coated sponge iron (Jaleel's process) for producing different steel alloys. Coated wax: (1) acts as inhibitor for inhibition of reoxidation of sponge iron. (2) provide the required carbon for reduction iron oxide as well as a balance for the chemical composition of steel. (3) provide part of the heat required for the reduction. (4) acts as a refiner for the steel via hydrogen formation in the slag which attacks impurities. Economic study was done show that (1) about 8-10\% reduction in the electric energy consumption with the new carbon - free waxed sponge iron comparing with that of normal sponge iron under the same melting conditions. (2) long life ( $\sim 20-25 \%$ more) for carbon electrode in the case of the new material melting comparing with that of normal sponge iron due to the reducing atmosphere created from the wax combustion during melting. (3) chemical analyses for produced steel show no traces of sulfur and phosphorous remain after melting. (4) calculation shows that there is a 5\% reduction in the total steel cost production in case of using 50\% sponge iron ( contain 5\% wax according to Jaleel waxing process) according to HYL costs system.
\end{abstract}

Keywords: Direct Reduced Iron, Wax, Steel, Electric Arc, Furnace

\section{Introduction}

The production of steel in (EAF) using sponge iron produced by Jaleel process as shown in Figure 1, in which water hydrogen from water electrolysis is used as reducing gas for the iron ore. The sponge iron produced by this process is carbon - free [1].

Over the past 20 years to use of EAF for the production of steel has grown considerably. There have been many reasons for this but primarily they all relate back to product cost and advances in technology. The capital cost per ton of annual installed capacity generally runs in the range of $140-200 \$ /$ ton for an EAF based operation . for a similar blast furnace (BOF) based operation the cost is approximately $1000 \$$ per annual ton of installed capacity. As a result EAF based operation have gradually moved into production areas that were traditionally made through the integrated route. The first of these areas was long products-reinforcing bar and merchant bar. This was followed by advance into heavy structural and plate products and most recently into the flat products area with the advancement of thin slab casting. At the current time, approximately $40 \%$ of the steel in North America is made via the EAF route. As the EAF producers attempt to further displace the integrated mills, several issues come into play such as residual levels in the steel (essentially elements contained in the steel that are not removed during melting or refining) and dissolved gases in the steel (nitrogen, hydrogen, oxygen).

Both of these have a great effect on the quality of the steel and must be carefully if EAF steelmakers are to successfully enter into the production of higher quality steels.

There have been many advances in EAF technology that have allowed the EAF to compete more successfully with the integrated mills. Most of these have dealt with increases in productivity leading to lower cost steel production [2].

Sponge iron can be used by EAF steelmakers as a part of their metallic charge, along with normal mill returns and, if required, with certain amounts of non selective cheap scrap. The many advantages associated with the use of sponge iron enable the EAF steelmaker to economically produce not only tight specifications steels, but also the tonnage plain carbon steels also. 


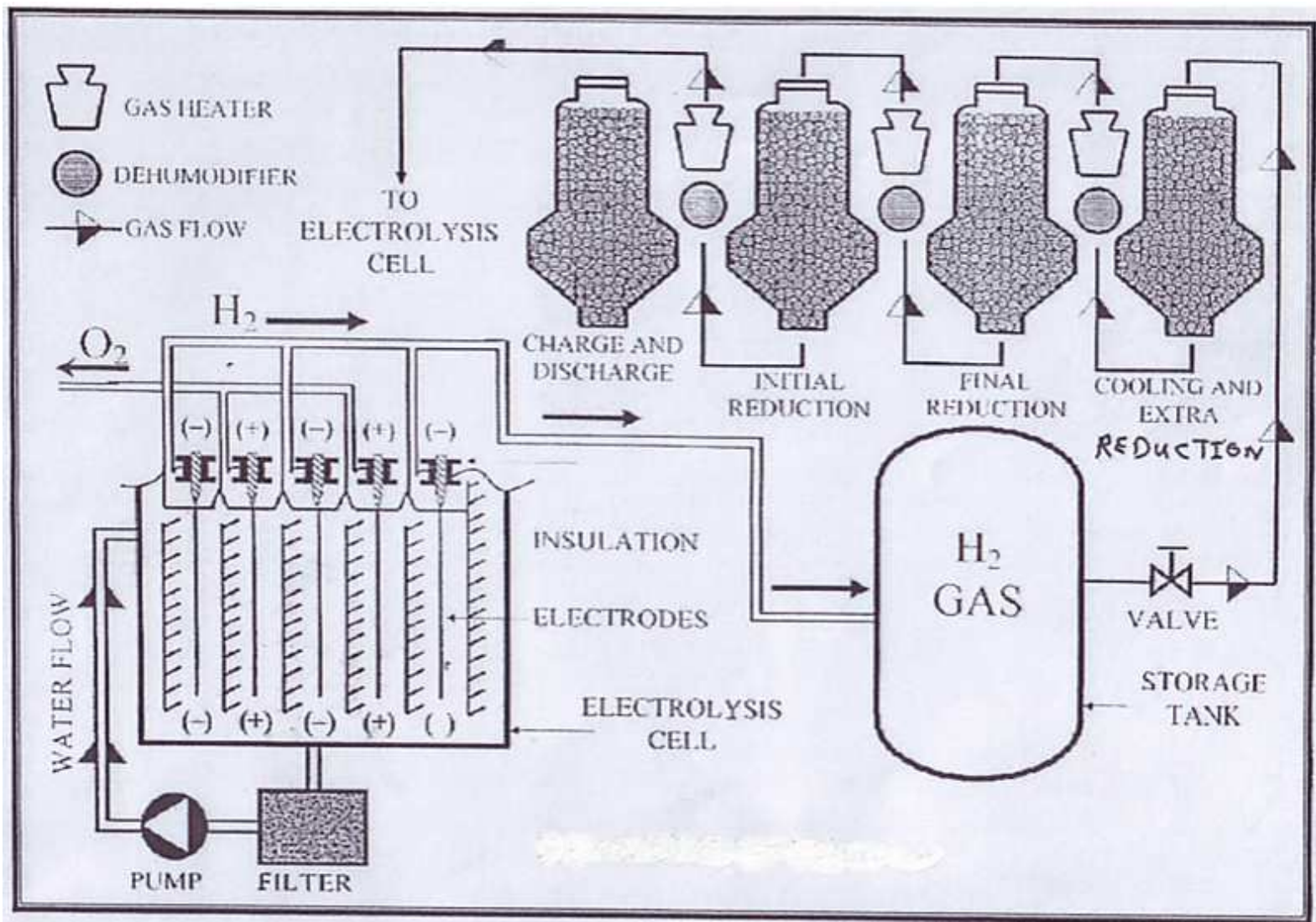

Figure 1. Jaleel - HYL Process.

\section{Discussion}

\subsection{Chemical Characteristics}

Sponge iron is a virgin iron containing no recycled tramp elements. Its analysis depends on the composition of the ore from which it was produced. Table 1 shows typical analysis or balanced sponge iron (Hyl product) and carbon-free sponge iron produced by Jaleel process. Sponge iron is a chemically uniform product if it is prepared from homogeneous ore. Such uniformity of the metallics source permits simplified and repetitive steelmaking practices. If the ore or oxide pellets are relatively low in sulfur and phosphorous. In case of using pure hydrogen as reducing gas only these two elements become very low in percents in the product sponge iron due to the high activity of pure hydrogen as reducing agent. Hydrogen attacks both elements in the slag (free or combined) at high temperature (see column 3 in Table 1).

$$
\begin{gathered}
\mathrm{H}_{2}+\mathrm{S}=\mathrm{H}_{2} \mathrm{~S} \quad \text { (Hydrogen sulfide gas) } \\
3 \mathrm{H}_{2}+2 \mathrm{P}=2 \mathrm{PH}_{3} \quad \text { (phosphine gas) }
\end{gathered}
$$

Thus no meltdown analysis for these elements is required and refining can very effectively be reduced to that required for
Table 1. Chamical analysis for balance and carbon-free sponge iron (using the same ore).

\begin{tabular}{lll}
\hline Specification & $\begin{array}{l}\text { Balance Sample \% } \\
\text { (HyL process) }\end{array}$ & $\begin{array}{l}\text { Carbon }- \text { Free sample \% } \\
\text { (Jaleel process) }\end{array}$ \\
\hline Metallization & 85 & 92 \\
Total iron & 87.9 & 91 \\
Carbon & 2.2 & - \\
Gangue & 3.8 & 4.2 \\
Lime & 2.3 & 2.4 \\
Oxygen & 3.8 & 2.39 \\
Sulfur & 0.014 & 0.002 \\
Phosphorous & 0.045 & 0.004 \\
Copper & 0.000 & 0.000 \\
Tin & 0.000 & 0.000 \\
Nickel & 0.020 & 0.025 \\
Chromium & 0.000 & 0.000 \\
\hline
\end{tabular}

Carbon and temperature adjustment. In case of Jaleel process, carbon is provided from burning and decomposition of wax coat which is used as inhibitor for reoxidation of sponge iron (Jaleel process) [3]. It is interesting to note that due to sponge iron's freedom from tramp elements, no deviations due to high residuals are experienced. In sponge iron, carbon is controlled and its variation is minimal. On the other hand, among the types of scrap, the difference in carbon content averages is up to $0.06 \%$ and is aggravated by a wide dispersion. In case of carbon free sponge iron, carbon is controlled from the burning and decomposition of wax coat in which carbon is deposited as very pure and fine 
particles and homogenously distributed over the charge [4].

\subsection{Physical Characteristic}

Additional advantages and incentives that sponge iron offers to the EAF steelmakers originate from its physical properties: the size, physical nature and uniformity in mechanical properties makes the prereduced material easy to handle, store and transport by simple means. It can be continuously fed to the EAF without complete installations. In case of carbon-free waxed sponge iron, no fines or dust generated during handling and charging to the furnace. These fines and dust are easly ignited and considered as lost material.

\subsection{Effect of the Wax on the Bath Activity}

It has long been recognized that an active bath is a requirement for the economic operation of the electric arc furnace in low carbon steel manufacture. The use of sponge iron in the feed offers the possibility of obtaining the desired activity by controlling the amount of gases produced during meltdown. If the prereduced material is not completely metallized and has enough carbon in the proper form to complete reduction during melt down, the carbon will be gasified to produce a mixture of carbon monoxide and carbon dioxide. In case of melting carbon-free waxed sponge iron, carbon is created from partially combustion wax which takes place over melt ( Furnace atmosphere) in case of continuous feeding or batch charged of sponge iron during rises furnace temperature as follow :-

$$
\mathrm{C}_{30} \mathrm{H}_{62}+\mathrm{O}_{2}=\mathrm{H}_{2} \mathrm{O}+\mathrm{C}+\mathrm{CO}+\mathrm{CO}_{2}
$$

The balance of the above reaction depends on the quantity of oxygen and the reaction temperature [4]. Some of coated wax will retain in the pellets while they sink through the slag to the slag- metal interface in case of continous feeding results in atomic decomposition of the wax in the slag:-

$$
\begin{gathered}
\mathrm{C}_{30} \mathrm{H}_{62}=30 \mathrm{C}+62 \mathrm{H} \\
62 \mathrm{H}=31 \mathrm{H}_{2}
\end{gathered}
$$

A generous gas evoluation is obtained from equations 3, 4, and 5 and from reaction of carbon with the remaining iron oxide in sponge iron plus that in the scrap:-

$$
\mathrm{C}+\mathrm{Feo}=\mathrm{Fe}+\mathrm{CO}+\mathrm{CO}_{2}
$$

and also from the attacks of atomic or molecular hydrogen to the impurities containing sulfur, phosphorous ,nitrogen etc in the slag. Such gas evolution is very desirable for several reasons which are listed below:-

1 formation of a foamy, lightweight insulating slag. With proper practice it is normal to expand the slag layer up to about four times, and have a slag depth of $0.5-0.7 \mathrm{~m}$, when operating with about $500 \mathrm{~kg}$ of slag per square meter of bath surface. This foamy slag is almost completely separated from the electrodes by the escaping gases generated at the arc. The arc forms at the metal- slag interface and is shielded by the thick slag layer, thus minimizing the direct radiation to wall and top linings and increasing furnace efficiency.

2 Minimizing extra-high temperature zones in the slag. Pirozhnikov[5] observes that the slag close to the electrodes is heated to extremely high temperatures by direct radiation from the arc and by contact with the hot metal vapours coming from the meniscus. This high radiation zone of incandescent slag may be eliminated if activity of the slag is made strong enough for fast renewal in the vicinity of the electrodes. This secondary radiation is thus minimized and heat absorbed by the slag is carried to areas where it is required for sponge iron heating and melting.

3 Lower temperature of the hot spot.

The meniscus of hot spot where the arc hits the metal is at an extremely high temperature. It is normally a spot of very high radiation and vigorous metal vaporization.

With the metal stirring associated with the gas generation, the metal is continuously renewed and the actual temperature at this point tends to the lower, thus reducing radiation and evaporation. Moreover, the heat is readly carried by the liquid metal from this source to regions where it will serve its useful purpose of melting the charge.

4 More efficient melting of continuously fed pellets.

When sponge is charged continuously it has no tendency to float above or in a slag that is maintained in a foamy state. Part of its wax (5-6\% by wt. of sponge iron) will partially combust (equation3) in the furnace atmosphere while the residue will be dewaxed during pellets penetration the foamy slag in which wax will be decomposed as in equations 4 and 5 . The sponge iron, be it pellets or lumps, will penetrate the foamy slag and work its way downward, heating up and reacting as it crosses the slag layer to the metal- slag interface where it will finally melt. Individual sponge iron pellets have an apparent specific weight of about 2.6 and will have a tendency to float over a still layer of molten slag that has a density of about $3.3 \mathrm{~g} / \mathrm{cm}^{3}$. This situation is aggravated by the gas generated within the pellet that may form bubbles on the surface. On the other hand, a good foamy slag will have an apparent density of less unity and the pellets will not float. During continuous feeding it is good practice to have the sponge iron stream somewhat spread out. In this manner, the individual pellets are preheated better while they sink through the slag to the slag- metal interface and in so doing they cool the slag, using its heat effectively and lowering slag radiation in addition to the dewaxing process and decomposition of the wax which are both heat absorber processes take place in the slag.

5 Reduction of dissolved oxygen, nitrogen, hydrogen etc. in the steel.

Physically with a generous gas evolution it is possible to reduce these gases concentrations dissolved in steel. When wax decomposed to carbon and hydrogen in the slag, hydrogen will attacks free nitrogen and oxygen or their compound in addition to sulfur and phosphorous compounds 
and in all cases gases are formed, thus these elements concentrations in the slag decreases result in concentration diffusion for these elements from the melt up to the slag (refinery process ).

6 Reducing Furnace Atmosphere

When part of the wax quantity burns in the furnace a atmosphere carbon, carbon monoxide, carbon dioxide , and water vapour are produced. The reducing properties of carbon monoxide and hydrogen [ which reacts with the oxygen of the furnace atmosphere to produce water vapour ) will minimize electrode penciling or consumption above the bath surface

\subsection{Balance Of Carbon-Free Sponge Iron by Wax}

"Balanced Sponge iron " is that which has just the necessary carbon content so that in the electric arc furnace it combines with the residual oxygen of the material itself, leaves unreduced the amount of $\mathrm{FeO}$ required by the slag and gives the desired carbon in the first analysis.

In order to make use of these desirable effects, the sponge iron must have carbon and residual unreduced $\mathrm{FeO}$ in suitable proportions. Carbon (in case of carbon - free sponge iron) provided from the decomposition of the coated wax in the furnace atmosphere in case of continuous feeding or in the charge in case of batch type (equations 3 and 4). Wax decomposition results in deposition of:

1 very pure carbon mainly in the form of carbon black.

2 very fine carbon particles.

3 very homogenous distribution in close contact with $\mathrm{FeO}$
The coated wax is in 5-6\% by weight of the sponge iron thus it contains $4.2-5 \%$ carbon in the coated sponge iron. From Table(1) Column(2) the carbon free sponge iron contains $9.3 \% \mathrm{FeO}$, so the theoretical carbon to balance equal to $1.57 \%$.

The metallizing capability of the carbon deposit, added to the metallization proper, will give us what is called equivalent metallization of the reproduced material. The metallizing capability of each one percent of carbon corresponds to an increase of about $6 \%$ metallization.

Early publications have used a factor $5+$ based on the assumption that all carbon gasifies to $\mathrm{CO}$. A detailed analysis shows that $\mathrm{CO}$ and $\mathrm{CO}_{2}$ are present in the proportion of six to one as required by equilibrium at a slag temperature of $1500^{\circ} \mathrm{C}$ (Figure 2) [6]. The corresponding factor is calculated from the following chemical reactions:

$$
\mathrm{C}+1.14 \mathrm{FeO}=1.14 \mathrm{Fe}+0.86 \mathrm{CO}+0.14 \mathrm{CO}_{2}
$$

One $\mathrm{kg}$ of carbon deposits from the decomposition of the wax reduces $1.14 \times 56 / 12=5.32 \mathrm{~kg}$ of Fe from $\mathrm{FeO}$.

Since the carbon - Free sponge iron (Table 1) has $91 \%$ total $\mathrm{Fe}, 1 \%$ of the gross weight in carbon reduces.

$5.32 / 0.91=5.85 \%$ of the total iron in the sponge.

The equivalent metallization is thus:

$\%$ equivalent metallization $=\%$ conventional met. $+5.85 \%$ C. In the following calculation, account is given of the heat of the chemical reaction of gasification of carbon that is present as free carbon and for the [4].

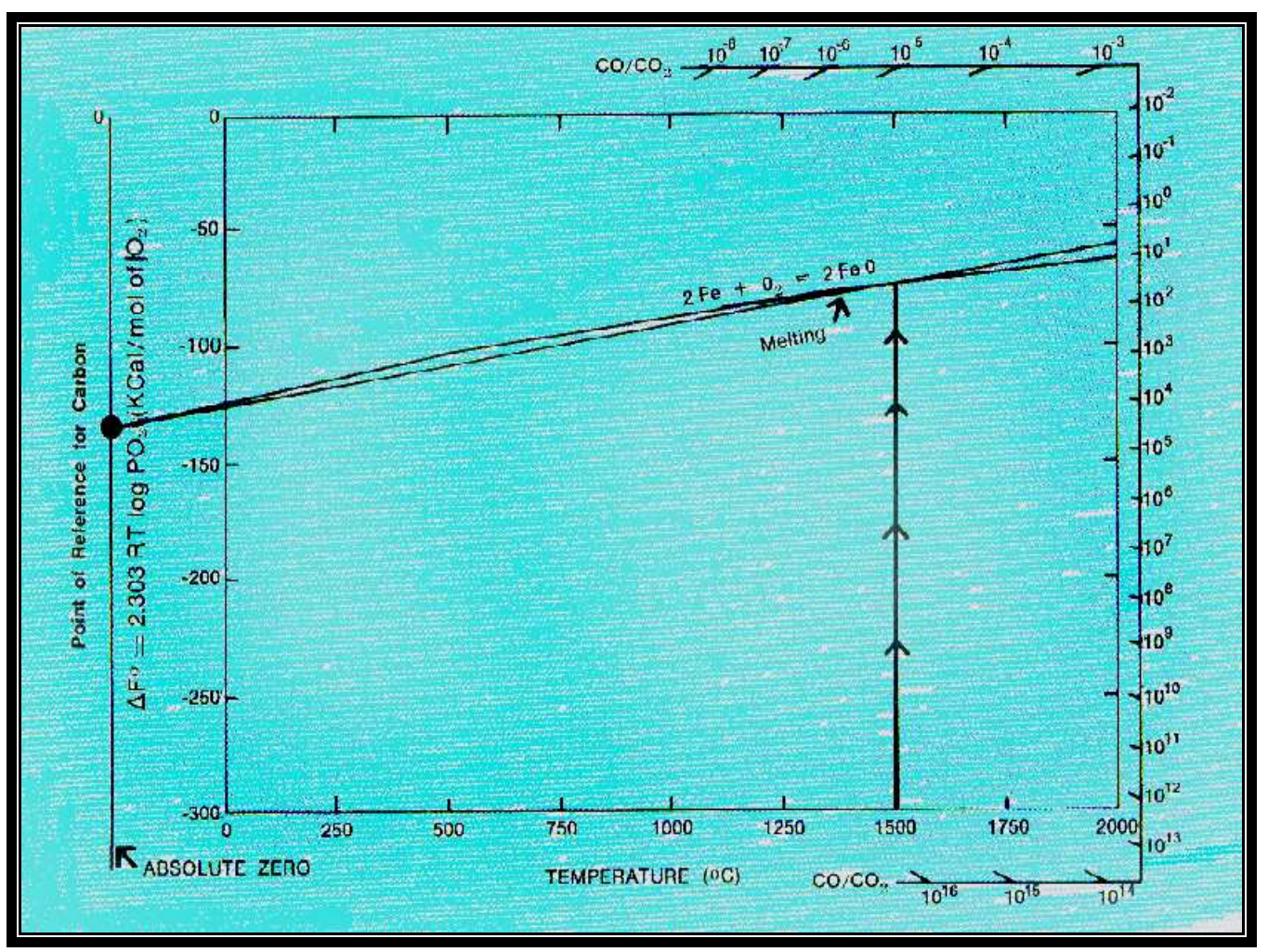

(Source: The Physical Chemistry of Iron and Steelmaking The Making, Shaping and Treating of Steel)

Figure 2. $\mathrm{CO} / \mathrm{CO}_{2}$ Ratio in The Reduction of FeO With Carbon 
Sensible heat contained in the escaping gases in kilo Joules per mol $\left(\mathrm{kJ} \mathrm{mol}^{-1}\right)$.

$$
\begin{gathered}
\mathrm{C}+1.14 \mathrm{FeO}=1.14 \mathrm{Fe}+0.86 \mathrm{CO}+0.14 \mathrm{CO}_{2} \\
\Delta_{\mathrm{r}} \mathrm{H}=\Delta_{\mathrm{F}} \mathrm{H}_{\mathrm{P}}-\Delta_{\mathrm{F}} \mathrm{H}_{\mathrm{R}}
\end{gathered}
$$

Heat of reaction $=\Sigma$ Heat of Formation of the product- $\Sigma$ Heat of formation of the reactants

$$
\begin{aligned}
\Delta_{\mathrm{r}} \mathrm{H} & =0.86(-110.54)+0.14(-393.5)-1.14(-267) \\
& =-95.06-55.09+304.38 \\
& =154.23 \mathrm{~kJ} \mathrm{~mol}^{-1}
\end{aligned}
$$

Sensible heats at $1800 \mathrm{~K}$ :

$$
\begin{aligned}
\Delta_{\text {escp }} \mathrm{H} & =0.86 \times 49.5+0.14 \times 79.4 \\
& =42.57+11.11=53.7 \mathrm{~kJ}
\end{aligned}
$$

$\therefore$ Heat required to reduce 1.14 moles of $\mathrm{Fe}$ from $\mathrm{FeO}$ including sensible heat in the escaping gases $=154.23+53.70$ $=207.93 \mathrm{~kJ}$

Worker shows that the above value can be reduced to more practical units by the transformation that gives $\mathrm{kWH}$ per ton of liquid steel for $1 \%$ metallization to take place in the electric furnace and before deduction of energy savings [6].

Also wax provided heat from its burning:-

One $\mathrm{kg}$ wax gives $\approx 43 \mathrm{~kJ}[7]$

Each ton sponge iron contains an average of $55 \mathrm{~kJ}$ wax.

$\therefore 55 \times 43=2365 \mathrm{~kJ} /$ ton coated sponge iron in case of complete combustion of the wax. Thus wax can compensate the heat required for reduction of the residual iron oxide [from both sponge iron and scrap].

\subsection{Melting Tests}

Several melting tests are carried on in different capacities electric arc furnaces of batch type (Figure 3).

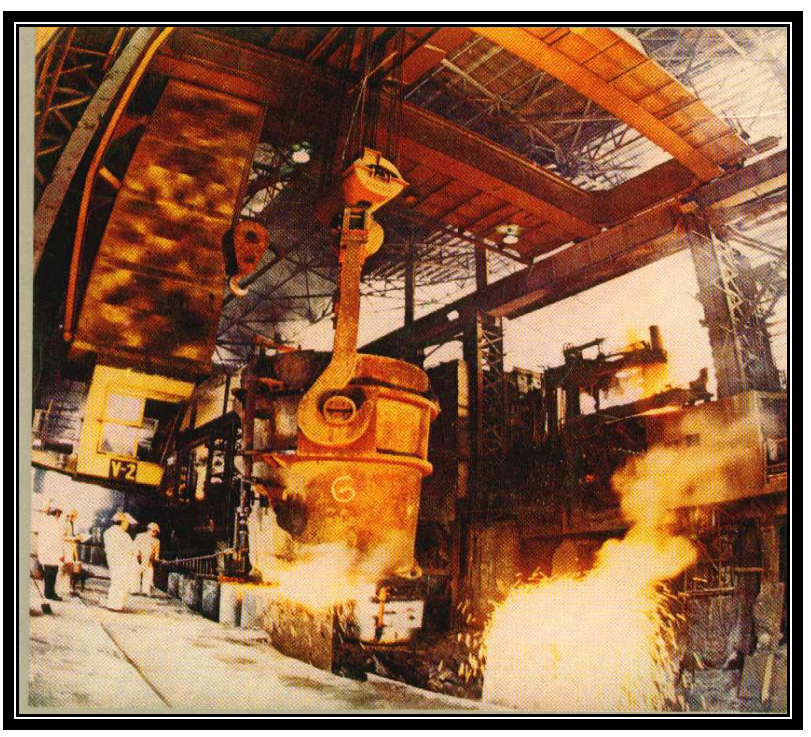

Figure 3. Foundry Shop for steel making.

\subsection{First Test (Low Carbon Steel)}

1.6 tons furnace capacity

0.6 ton scrap with known chemical composition is feeded at $500^{\circ} \mathrm{c}$, then 1 ton carbon- free wax coated sponge iron. Low carbon steel produced with good mechanical properties.

\subsection{Several Tests (High Chromium Steel)}

5 tons furnace, capacity

$50 \%$ sponge iron is feeded with $30 \%$ scrap and $20 \%$ ferrochromium to produce mill balls for cement industry. About 20 tons carbon- free wax coated sponge iron are melted for production of this steel with good properties.

No facility for continuous feeding to carry on test.

\section{Conclusion}

1. No problem with the melting of new carbon- free wax coated sponge iron for production different steels.

2. Coated wax has multifunction in this industry

(a)acts as inhibitor for inhibition of reoxidation of sponge iron.

(b)Provide the required carbon for reduction iron oxide.

(c)Provide part of the heat required for the reduction.

(d)acts as refiner for the steel via hydrogen formation in the slag which attacks impurities

\subsection{Economic Study}

Economic study was done with the helpness of the foundry plant. It is appeared that:

About $8-10 \%$ reduction in the electric energy consumption with the new carbon-free waxed sponge iron comparing with that of normal sponge iron under the same melting conditions.

Long life $(20-25 \%$ more $)$ for carbon electrodes in the case of the new material melting comparing with that of normal sponge iron due to the reducing atmosphere created from the wax combustion during melting.

Chemical analyses show no traces of sulfur and phosphorous (which are present already in the normal sponge iron) remain after melting of the new material due to the attacks of hydrogen created from decomposition of wax to both elements during melting. Both sulfur and phosphorous have bad effects on the mechanical properties of the manufacturing steel. Mechanical tests for both sponge iron show that clearly. This reflects that higher quality steel can be produced from melting of the new waxed sponge iron.

From points 1 and 2, calculation shows that there is a 5\% reduction in the total steel costs production in case of using $50 \%$ sponge iron according to HyL costs system. Since the cost of one metric ton steel production in Iraq now $=450 \$$.

$\therefore$ there is a reduction of $22.5 \$$.

\subsection{Present and Future Iraqi Market of Iron and Steel}

The present Iraqi market of iron and steel is completely not clear and is depended mainly on the free importation of steel 
by the private sector only and can be summarize as follows:

- Imported reinforcing bars from Iyran and Ocranya with 470-480\$ per ton for consumer. Price depends on the origin country.

- Imported rail bars from Iyran and Ocranya with 6-6$8 \$$ per meter for consumer. Price depends on the origin country.

- First class local scrap with $70 \$$ per ton.

- Second class local scrap with $50 \$$ per ton.

- Most scrap quantity exports to the neighbor countries due to shutt down of the most local foundries due to the shortage in the electrical energy.

- The expect Iraqi demands on steel for 2006 is in the range of 2-2.5 million tons. Because in this year may be rebuilding starts.

- Now the government do not interest in building iron and steel projects, such industry consumes high electrical energy which is now not available. Iraq needs five years from now to builds electricity projects sufficient to the requirement. Thus iron and steel projects are link with the electrical energy production.

- private sector is also not seriously interesting in such project due to the above reasons. Recently acceptances performed to build up private boundary project with capacity of -400000 ton/ year reinforcing bars depending on the local scrap. The contractor company provides the project with diesel generator, this may be put the product in hard competion position with the imported one, as well as the production of this project not enough for Iraqi market demands, so it is difficult or impossible to protect its production by stopping or reducing the steel importation by the government.

- Governmental and private sectors foundries face a high shortage in electrical energy and raw materials, thus they depend mainly on local scrap of intermediate quality thus their production are discontinuous and in low productivity that only resembles about $5 \%$ of Iraqi market demand now. The produced reinforcing bars with a price of $450 \$$ for the consumer, but the latter prefers the imported one due to its quality and availability in the market.

- May be the governmental foundries will get sponge iron from Hadeed (Saudi iron and steel company) for steel making but this step depends on the production growth of electrical energy, this will result in stopping of scrap exportation and this will reflect on the reduction of its price in future.

- cast iron production is not affected by these circumstances. This is because it produces mainly by private sector with low quantity and medium quality.

- No production of high alloys steel in Iraq. Completely finshed stainless steel imports for direct usages by consumer, such as kitchenware and technical tools... etc, and it is available always in the market. Note that Iraq plans to produces stainless steel in 1980's, but the project is not appear up to date. Iraq imports stainless steel from India with price of $3500 \$$ per ton for the consumer.

- Most of governmental foundries are remaintenanced and rehabilated, but their productivities are lower than their design capacities due to the above problems.

- Iraq demands through the commencing four years between 10-12 millions ton of different kinds of steel. About $80 \%$ of the above quantity will be imported, after that governmental and private foundries will be in full capacity production beside new foundaries and new sponge iron plant will be in their performance way at that time.

- waxing process will be used for storage and transportation of sponge iron to prevent its oxidation and ignition and we expect that hydrogen of the water will be the reducer of iron oxide. Both of these processes are well known in the Iraqi ministry of industry and minerals.

- The general direction of the government is to activate the private sector towards steel down stream industries after provides the facilities required for these industries by the government.

\section{References}

[1] Dr. Jaleel Kareem Ahmed and Eng. Haidar Jaleel Kareem, Water Hydrogen use in DRI-Industry, Arab Steel - No.331 Sempteber-2003.

[2] J. A. T. Jones, B. Bowman, and P. A. Lefrank, Electric Furnace Steel Making, Arab Steel No. 331 Sept. 2003.

[3] Dr. Jaleel Kareem Ahmmed, $7^{\text {th }}$ International Iron and Steel Conference 2004, Stimulating and Encouraging Reasons for Future Expansion in DRI and Steel in Iraq, Arab Steel No. 342 September 2004.

[4] Dr. Jaleel Kareem Ahmed, Carburizing of Steel, Iraqi patent No. 1480.

[5] V. E. Pirozhnikov, "Effect of Slag on thermal processes in the Electric Furnaces", Stal, March 1967, PP222-224.

[6] Juan Celada S., Technical Vice-President, AlFa Steel Division, June 1978.

[7] Warth, the Chemistry and technology of Waxes, Reinhold Publishing Corporation, New York, 1956. 